\title{
A New Approach to Objective Evaluation of the Success of Nasal Septum Perforation
}

\author{
Sinan Ozturk ${ }^{1}$, Fatih Zor ${ }^{2}$, Serdar Ozturk², Ozgur Kartal ${ }^{3}$, Dogan Alhan², Selcuk Isik ${ }^{2}$ \\ ${ }^{1}$ Deperatment of Surgery, Gulhane Military Medical Academy, Haydarpasa Training Hospital, Istanbul; ${ }^{2}$ Deperatment of Plastic and \\ Reconstructive Surgery, Gulhane Military Medical Academy, Ankara; ${ }^{3}$ Deperatment of Allergy, Gulhane Military Medicine Academy, Ankara, \\ Turkey
}

Background Perforations in the nasal septum (NSP) give rise not only to disintegration of the septum anatomy but also impairment in normal nasal physiology. The successes of these surgical techniques are usually equated to anatomical closure of the perforation. The goal of this study is to evaluate the subjective and objective results of our surgical technique for septal perforation surgery.

Methods All NSPs in the six patients were closed by inferior turbinate flap. The Nasal Obstruction Symptom Evaluation (NOSE) instrument was used to evaluate the preoperative and postoperative subjective sensation of nasal obstruction. Measurement of preoperative and postoperative nasal airway resistance was performed using active anterior rhinomanometry which is an objective test. Wilcoxson signed rank test and Spearman correlation test were used to analyze correlation between NOSE scores and rhinomanometric measurements.

Results The full closure of the septal perforations was noted in 100\% of patients. The total NOSE score was 14 preoperatively and one postoperatively. The improvement in NOSE scores was statistically significant $(P \leq 0.002)$. The mean preoperative total resistance (ResT150) value was $0.13 \mathrm{~Pa} / \mathrm{cm}^{3} \mathrm{~s}^{-1}$, which is below the normal range $\left(0.16-0.31 \mathrm{~Pa} / \mathrm{cm}^{3} \mathrm{~s}^{-1}\right)$, while the mean postoperative ResT150 value was $0.27 \mathrm{~Pa} / \mathrm{cm}^{3} \mathrm{~s}^{-1}$. The correlation between the improvement in NOSE scores and improvements in ResT150 values was statistically significant .

Conclusions Surgical approaches should aim to solve both the anatomical and physiological problems of NSP. The application of subjective and objective tests in the postoperative period will help surgeons assess the applied techniques.

Keywords Nasal / Perforation / Rhinomanometry / Surgery
Correspondence: Sinan Ozturk Deperatment of Surgery, Gulhane Military Medical Academy, Haydarpasa Training Hospital,

Selimiye district, Tıbbiye st., 34668 Uskudar, Istanbul, Turkey Tel: +90-216-542-4205 Fax: +90-216-222-4690 E-mail: ozturksinan@hotmail.com

This article was presented at the $32 n d$ Conference of Turkish Society of Plastic Reconstructive, and Aesthetic Surgery on October 10-14, 2010 and awarded for "Second Best Study" in clinical research.

This article was accepted (not presented) as oral session at the American Society for Aesthetic Plastic Surgery (ASAPS) Annual Meeting May 6-11, 2011 on Boston (couldnt be presented for the technical reasons).

No potential conflict of interest relevant to this article was reported.

Received: 28 Apr 2014 • Revised: 7 Jul 2014 • Accepted: 7 Jul 2014

pISSN: 2234-6163 • elSSN: 2234-6171 • http://dx.doi.org/10.5999/aps.2014.41.4.403・Arch Plast Surg 2014;41:403-406

\section{INTRODUCTION}

Nasal septum perforation can be described as an anatomical defect in the nasal septum. It can include cartilaginous, bony or both parts of the nasal septum. There are many etiologic reasons, such as traumas (septal resection and septorhinoplasty), drugs, chemicals, neoplasia, inflammatory diseases and infections, for nasal septal perforations [1]. Perforations in the nasal septum give rise not only to disintegration of the septum anatomy but also the impairment of normal nasal physiology [2]. Anatomical and physiological changes following perforation result in many different symptoms, such as a sensation of nasal ob- 
struction, epistaxis, crusting, dryness, headache and whistling sounds [3].

Different surgical and nonsurgical techniques have been performed, with varying degrees of success, to close nasal septal perforations [4]. The successes of these surgical techniques are usually equated to anatomical closure of the perforation and symptomatic relief. Subjective appraisal following nasal surgery can be assessed with different scoring charts. The Nasal Obstruction Symptom Evaluation (NOSE) is one of the most highly used scoring systems [5]. Even though relief in subjective symptoms of patients is important, an objective measurement of nasal physiology should be performed. Applying an objective assessment of preoperative and postoperative nasal septal physiology provides an opportunity to compare the physiologic results of various surgical procedures and can lead to the identification of the ideal method. Rhinomanometry (RMM) tests nasal airway resistance by measuring nasal airflow and the pressure produced by nasal airflow [6]. RMM have been used for the evaluation of various nasal surgical techniques [7]. The goal of this study is to evaluate the subjective and objective results of our surgical technique for septal perforation surgery.

\section{METHODS}

Thirteen patients presented to the our clinic with symptomatic nasal septal perforation. Of these patients, seven had a concomitant nasal pathology, such as nasal septal deviation, conchal hypertrophy and synechiae, and were excluded from the study. The remaining six patients were included in our study. The Clinical Research Council at our hospital approved the study protocol.

\section{Surgical technique}

Our flap choice for the closure of septal perforations in all patients was the posterior pedicled inferior turbinate flap (ITF). All operations were performed under general anesthesia by the same surgical team. After epinephrine $(1: 100,000)$ infiltration for hemostasis, the open rhinoplasty approach was performed to harvest the inferior turbinate. The edge of the perforation was trimmed to remove the damaged zone. After the advancement and adjustment to fill the perforation, the flap was sutured, using 4-0 absorbable polyglactin sutures, to the septum (Fig. 1). The pedicle was released six weeks later in an outpatient second stage procedure under local anesthesia.

\section{Nasal endoscope}

All patients underwent nasal endoscopic examination with $0^{\circ}$ and $45^{\circ}$ endoscopes to evaluate the septum, both nasal cavities,

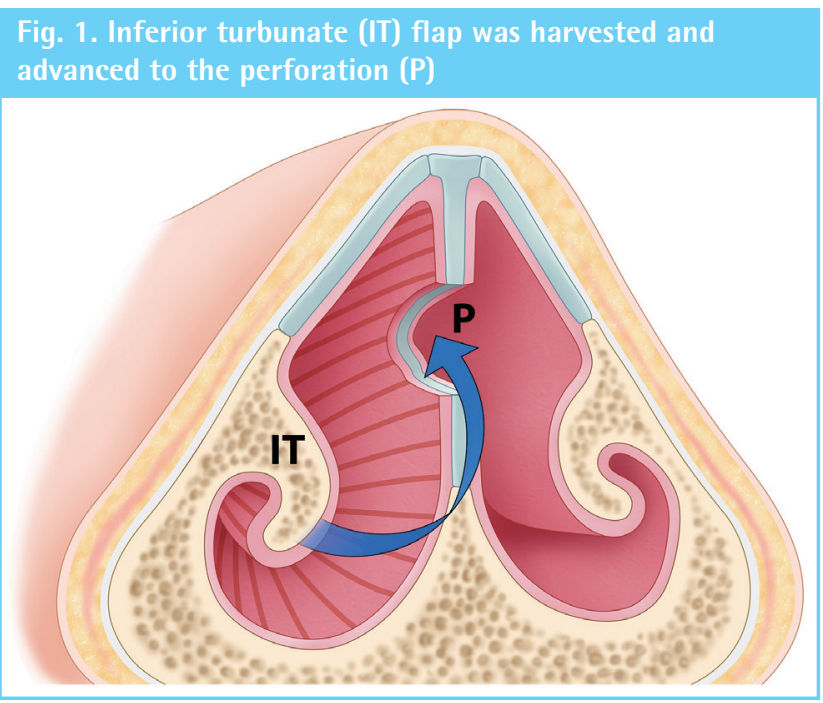

and mucosal changes (bleeding, crusting). The size and the locations of the septal perforations were measured by ruler during the nasal endoscopic examination. For comparison, all patients underwent endoscopic examination preoperatively and at two months postoperatively.

\section{NOSE instrument}

The NOSE instrument was used to produce a severity score of subjective symptoms (nasal congestion, obstruction, trouble breathing, trouble sleeping, unable to get enough air). The scale scores are within the range of 0 to 4 (scores: 0 , not a problem; 4 , severe problem). For comparison, the NOSE scale was applied preoperatively and two months later in a postoperative follow-up.

\section{Rhinomanometry}

Measurement of nasal airway resistance was performed using active anterior RMM (ZAN200, ProvAir II, Oberthulba, Germany). The rhinomanometric measurements were performed under the same standard condition by the same technician. Recommendations of the International Standardization Committee for RMM were followed during all measurements [8]. The flow at a pressure of $150 \mathrm{~Pa}$ was the sample pressure. The nasal patency was measured in units $\mathrm{Pa} / \mathrm{cm}^{3} \mathrm{~s}^{-1}$. Each nasal airway was tested separately and total airway resistance (ResT150) was obtained. Active anterior RMM was performed preoperatively and two months later in a postoperative follow-up.

\section{Statistical analysis}

Statistical analysis of the results was performed using a software system (SPSS, Inc., Chicago, IL, USA). The Spearman correlation test was used to analyze correlation between NOSE scores and rhinomanometric measurements. A P-value $\leq 0.05$ was 


\begin{tabular}{|c|c|c|}
\hline \multirow{2}{*}{ Patient } & \multicolumn{2}{|c|}{ NOSE score } \\
\hline & Preoperative & Postoperative \\
\hline 1 & 14 & 1 \\
\hline 2 & 11 & 0 \\
\hline 3 & 16 & 2 \\
\hline 4 & 15 & 1 \\
\hline 5 & 14 & 0 \\
\hline 6 & 14 & 2 \\
\hline Mean & 14 & 1 \\
\hline
\end{tabular}

considered statistically significant.

\section{RESULTS}

All patients were male and their mean age was 31.4 years (range, 21-42 years). A trauma, secondary to previous septal surgery, was the sole etiologic reason for the septal perforation in all patients (100\%). Preoperative symptoms include a sense of nasal obstruction (100\%), crusting (50\%), epistaxis (33\%), whistling (16.6\%), and headache (16.6\%). The vertical length of the perforation ranged from 9 to $17 \mathrm{~mm}$ (mean, $12.8 \mathrm{~mm}$ ) and the horizontal length ranged from 8 to $25 \mathrm{~mm}$ (mean, $13.4 \mathrm{~mm}$ ). The follow up period was 8 months on average, with a range of 6-12 months. The total NOSE score was 14 preoperatively and one postoperatively. The improvement in NOSE score was statistically significant $(\mathrm{P} \leq 0.002)$ (Table 1$)$. None of the patients had epistaxis, crusting, whistling, and headache during the postoperative follow-up period. The mean preoperative ResT150 value was $0.13 \mathrm{~Pa} / \mathrm{cm}^{3} \mathrm{~s}^{-1}$, which is below the normal range. In contrast, the mean postoperative ResT150 value was $0.27 \mathrm{~Pa} / \mathrm{cm}^{3} \mathrm{~s}^{-1}$, which is in the normal range ${ }^{6}$. The difference between the preoperative and postoperative ResT 150 value was not statistically significant $(\mathrm{P} \geq 0.05)$. The correlation between the improvement in NOSE score and the improvement in ResT150 value was statistically significant with $95 \%$ confidence interval (Fig. 2).

\section{DISCUSSION}

Many surgical techniques have been introduced for the reconstruction of nasal septal perforations [9]. Every surgical approach has its own advantages and disadvantages, as does our technique (ITF) [10]. Depending on the size or location of the perforation, treatment method and flap choice can be different. This study did not address flap choices or their surgical advan-

\section{Fig. 2. The scatterplot of NOSE score and ResT150 values}

Spearman's nonparametric correlation test showed a positive correlation between improvement in NOSE scores and ResT150 values. NOSE, Nasal Obstruction Symptom Evaluation.

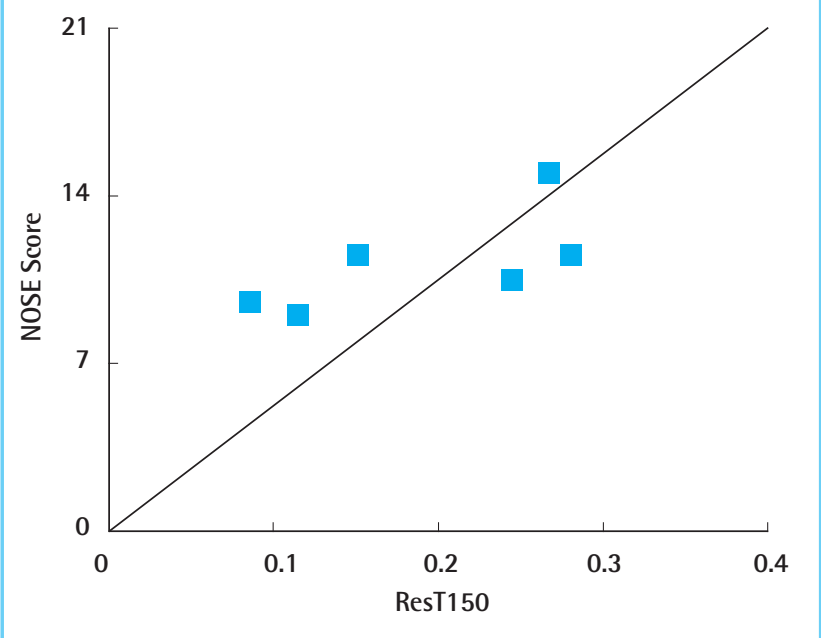

tages and disadvantages. Instead, it focused on the affect of the ITF technique on objective and subjective measures of surgical success. In past studies, the success of a surgical approach has been represented by the closure rate [11-13]. The closing of the septal perforation only deals with anatomical aspects of the problem. Besides the anatomical defect, nasal septal perforation results in impairments of nasal physiology [14-17]. There are a limited number of studies referring to symptom control in patients with nasal septal perforations who receive surgical treatments [18]. In this study, we tried to analyze the physiological effect of our surgical approach using objective tests and to establish correlations between subjective findings.

Normal nasal airflow follows a laminar path [19]. In septal perforations, laminar flow is compromised and turbulent airflow occurs [20]. This turbulent flow is the main cause of the crusting, bleeding and whistling sound. As expected, we found low total nasal airway resistance $\left(0.13 \mathrm{~Pa} / \mathrm{cm}^{3} \mathrm{~s}^{-1}\right)$ preoperatively. After closing the perforation with an inferior turbinate flap, total nasal airway resistance reached the normal range in all patients $\left(0.27 \mathrm{~Pa} / \mathrm{cm}^{3} \mathrm{~s}^{-1}\right)$. The difference between the preoperative and postoperative ResT150 value was not statistically significant $(P \geq 0.05)$, although the lack of significance may be the result of an insufficient number of patients. Along with improvements in nasal physiology, we observed improvements in symptom control. We confirmed the improvement by using the NOSE scale, which is a valuable tool for rhinologic complaints, especially in cases of nasal obstruction. We showed that there was a correlation between the symptom control and improvements in nasal physiology. It is important to quantify surgical 
outcomes with objective tests. Especially after rhinologic surgeries (septoplasty, rhinoplasty, conchal surgery, etc.), there can be a divergence between the objective and subjective findings [21]. The main limitation of our study was the limited number of patients. A larger study, which would have greater statistical power, is warranted. In conclusion, nasal septal perforation results in a double-sided problem, anatomical and physiological. Surgical approaches should address both of these issues. The application of subjective and objective tests during the postoperative period will help surgeons assess the applied techniques.

\section{REFERENCES}

1. Kridel RW. Considerations in the etiology, treatment, and repair of septal perforations. Facial Plast Surg Clin North Am 2004; 12:435-50.

2. Leong SC, Chen XB, Lee HP, et al. A review of the implications of computational fluid dynamic studies on nasal airflow and physiology. Rhinology 2010;48:139-45.

3. Pallanch JF, Facer GW, Kern EB, et al. Prosthetic closure of nasal septal perforations. Otolaryngol Head Neck Surg 1982; 90:448-52.

4. Kridel RW. Septal perforation repair. Otolaryngol Clin North Am 1999;32:695-724.

5. Stewart MG, Smith TL, Weaver EM, et al. Outcomes after nasal septoplasty: results from the Nasal Obstruction Septoplasty Effectiveness (NOSE) study. Otolaryngol Head Neck Surg 2004;130:283-90.

6. Clement PA. Committee report on standardization of rhinomanometry. Rhinology 1984;22:151-5.

7. Broms P, Jonson B, Malm L. Rhinomanometry. IV. A preand postoperative evaluation in functional septoplasty. Acta Otolaryngol 1982;94:523-9.

8. Clement PA, Gordts F; Standardisation Committee on Objective Assessment of the Nasal Airway, IRS, and ERS. Consensus report on acoustic rhinometry and rhinomanometry. Rhinology 2005;43:169-79.

9. Park JH, Kim D, Jin HR. Nasal septal perforation repair using intranasal rotation and advancement flaps. Am J Rhinol Allergy 2013;27:e42-7.

10. Friedman M, Ibrahim H, Ramakrishnan V. Inferior turbi- nate flap for repair of nasal septal perforation. Laryngoscope 2003;113:1425-8.

11. Kridel RW, Appling WD, Wright WK. Septal perforation closure utilizing the external septorhinoplasty approach. Arch Otolaryngol Head Neck Surg 1986;112:168-72.

12. Kridel RW, Foda H, Lunde KC. Septal perforation repair with acellular human dermal allograft. Arch Otolaryngol Head Neck Surg 1998;124:73-8.

13. Woolford TJ, Jones NS. Repair of nasal septal perforations using local mucosal flaps and a composite cartilage graft. J Laryngol Otol 2001;115:22-5.

14. Pless D, Keck T, Wiesmiller KM, et al. Numerical simulation of airflow patterns and air temperature distribution during inspiration in a nose model with septal perforation. Am J Rhinol 2004;18:357-62.

15. Lindemann J, Leiacker R, Stehmer V, et al. Intranasal temperature and humidity profile in patients with nasal septal perforation before and after surgical closure. Clin Otolaryngol Allied Sci 2001;26:433-7.

16. Grant O, Bailie N, Watterson J, et al. Numerical model of a nasal septal perforation. Stud Health Technol Inform 2004; 107:1352-6.

17. Lee HP, Garlapati RR, Chong VF, et al. Effects of septal perforation on nasal airflow: computer simulation study. J Laryngol Otol 2010;124:48-54.

18. Stewart MG, Witsell DL, Smith TL, et al. Development and validation of the Nasal Obstruction Symptom Evaluation (NOSE) scale. Otolaryngol Head Neck Surg 2004;130:15763.

19. Mlynski G, Grutzenmacher S, Plontke S, et al. Correlation of nasal morphology and respiratory function. Rhinology 2001;39:197-201.

20. Grutzenmacher S, Mlynski R, Lang C, et al. The nasal airflow in noses with septal perforation: a model study. ORL J Otorhinolaryngol Relat Spec 2005;67:142-7.

21. Sipila J, Suonpaa J. A prospective study using rhinomanometry and patient clinical satisfaction to determine if objective measurements of nasal airway resistance can improve the quality of septoplasty. Eur Arch Otorhinolaryngol 1997; 254:387-90. 